\title{
AN EXPLORATORY INVESTIGATION OF E-BUSINESS CONSTRAINTS AMONG LARGE ORGANIZATIONS IN PORTUGAL
}

\author{
Elisabete Morais, José Adriano Pires \\ Instituto Politécnico de Bragança, Bragança, Portugal \\ beta@ipb.pt, adriano@ipb.pt \\ Ramiro Gonçalves \\ Universidade de Trás-os-Montes, Vila Real,Portugal \\ ramiro@utad.pt
}

Keywords: Stages of growth, e-business progression, constraints.

Abstract: It is well recognized that e-business supports all parts of an organization's value chain, and offer valuable competitive advantages to firms. It is imperative for an organization to identify potential constraints to ebusiness in order to minimize the risk derived from its e-business initiative. Hence, in this paper, we explore a range of constraints that the literature suggests influences e-business evolution, so that organizations could be better equipped in anticipating any difficulties while in progress through their e-business initiatives. Thirteen hypotheses were formulated and tested. Questionnaires were applied to investigate the research problem. It was administered to 1000 managing directors of the biggest (according to the amount of business) Portuguese enterprises. Results suggest that organizational constraints are more critical, such as, conflict with traditional trading partners, conflict with traditional business and e-business initiatives, reengineering business processes and resistance to change, among other.

\section{INTRODUCTION}

New economy, new tools, new rules. Few concepts have revolutionized business more profoundly than e-business. To compete effectively in the e-business world, a company must structurally transform its internal foundation. This structural change requires a company to develop an innovative e-business strategy, focusing on speed to market and breakthrough execution (Kalakota and Robinson, 2000).

The present paper explores the constraints associated with e-business evolution. Were identified environment, organizational and technological constraints. We want to explore if the constraints are equal for all e-business maturity stages.

The remainder of the paper is organized as follows: the next section reviews the concept of ebusiness; sections 3 and 4 briefly discuss the research model and data collection. Section 5 presents and discusses the results obtained.

\section{DEFINING E-BUSINESS AND MATURITY MODELS}

The terminology involved within the field of Information Communication Technology (ICT) usage on the Internet is vast and contradictory. Two frequently used terms are e-commerce and ebusiness.

Kalakota and Whinston (1996) define electronic commerce as the "... buying and selling of information, products and services via computer networks". Laudon and Travel (2006) define electronic commerce as the "use of the Internet and the Web to transact business". Sewell and McCarthey (2001) identify electronic business as business facilitated by ICT. Others argue that electronic business encompasses the entire word of internal and external electronically based activities, including electronic commerce (Kalakota and Robinson, 2003). In the scope of this paper, 
electronic commerce will be regarded as a subset of electronic business.

Based on various types of trading partners, there are many categories of e-business. Without the use of face to face operations, all e-business transactions are performed electronically by using computer and communication networks. The three principal categories of e-business applications are (Phan, 2003):

1. Electronic markets or e-marketplaces: buying and selling goods and services.

2. Inter-organizational systems: facilitating inter and intra-organization flow of goods, services, information, communication, and collaboration.

3. Customer service: providing customer service, help, handling complaints, tracking orders, etc.

Since the introduction of computer technology into organizations in the 1960s, there have been numerous attempts to develop models of Information Systems/Information Technology (IS/IT) maturity. These models are premised on the idea that organizations pass through stages of maturity with respect to the way they use and manage IS/IT to support and facilitate business activities, processes and operations.

\section{RESEARCH MODEL AND HYPOTHESES}

The research model includes e-business constraints and e-business maturity as shown in Figure 1. Being an early, exploratory study, the focus was on primary associations. A single stage model was adopted that directly related dependent variables with independent variables without any intermediate variables. We first looked at e-business maturity and then at e-business constraints, and then we developed the hypotheses. The focus is on the biggest (according to the amount of business) Portuguese enterprises.

\subsection{E-business maturity}

Therefore, in order to explain the progression of e-business in the context of the Portuguese enterprises, we used the Stages of Growth for ebusiness model (SOGe). As with all other stages of growth models, the SOGe model assumes that a normal progression is from a less mature to an increasing sophistication over time (Prananto et al., 2003).

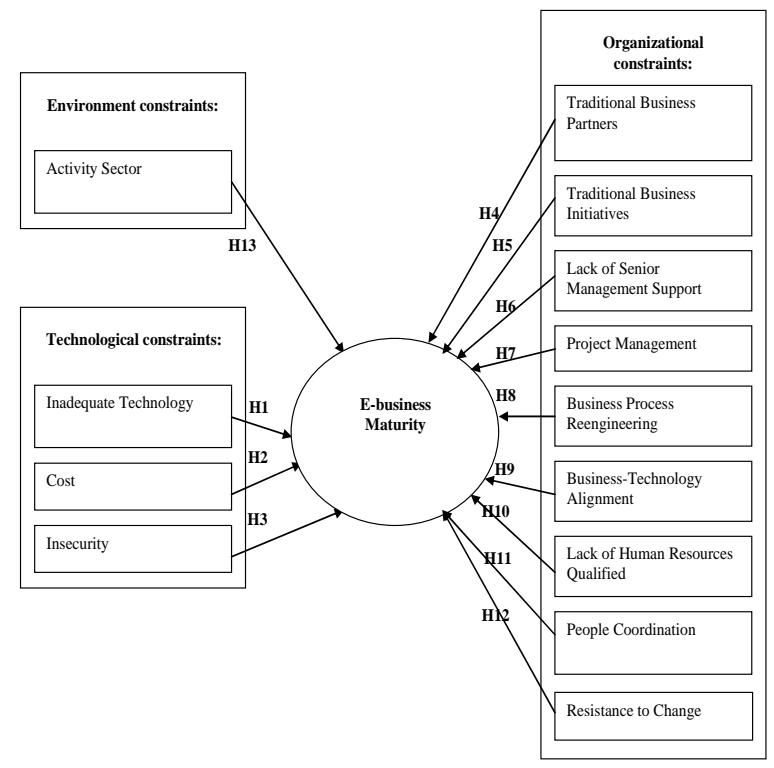

Figure 1: The conceptual model.

\subsection{E-business constraints}

The literature suggests various factors that inhibit the e-business development, including: Environment constraints; Organizational constrains; and Technological constraints.

HO: The constraint "Inadequate technology" is the same for all e-business maturity stages.

H1: There are at least two stages of maturity with significantly different average.

The technology is obviously the driver of the ebusiness (Bakry and Bakry, 2001).

H0: The constraint "Cost" is the same for all e-business maturity stages.

H2: There are at least two stages of maturity with significantly different average.

The cost of technology is enormous (Grover et al., 1998, Legris et al., 2003), hence this could be one of the constraints of the e-business.

H0: The constraint "Insecurity" is the same for all ebusiness maturity stages.

H3: There are at least two stages of maturity with significantly different average.

A huge success factor in any e-business initiative is the security (Worner, 2002). The uncertainty regarding the security aspects, the lack of trust in virtual relationships may affect the success of ebusiness (Chepaitis, 2002).

H0: The constraint "Conflicts with traditional business partners" is the same for all e-business maturity stages.

H4: There are at least two stages of maturity with significantly different average. 
If the traditional business partners don't adhere to this new way of doing business, conflicts with it could be a constraint to the development of ebusiness. One of the first steps in the evolution of ebusiness is to improve relations with key partners in traditional business (Eisenmann, 2007).

H0: The constraint "Conflicts with traditional business initiatives" is the same for all e-business maturity stages.

H5: There are at least two stages of maturity with significantly different average.

It is Porter's (2001) belief that a successful company in the real world should take advantage of its brand and its other assets to become stronger in the digital world. In defining a strategy based on electronic business, it is essential to define how it will manage the conflict between the business online and offline business (or traditional). For this, it will prevent the new channel (online) to compete directly with the businesses already established in the same group of customers (cannibalization effect). Thus, the existence of conflicts between these two channels may be a constraint to the development of e-business.

H0: The constraint "Lack of senior management support" is the same for all e-business maturity stages.

H6: There are at least two stages of maturity with significantly different average.

The support of top management is generally accepted as being critical to the success of ebusiness. This is because the leader of the company is usually the main decision maker because of the influence he has on the allocation of key resources (Lertwongsatien and Wongpinungwatana, 2003; Martin and Matlay, 2003). Sorenson (2000) also found a positive association between a participatory leadership of the leader and the performance of electronic business.

H0: The constraint "Project management" is the same for all e-business maturity stages.

H7: There are at least two stages of maturity with significantly different average.

E-business projects, as all other projects of the organization, need to be evaluated and monitored (Grembergen and Amelinckx, 2002).

H0: The constraint "Business process reengineering" is the same for all e-business maturity stages.

H8: There are at least two stages of maturity with significantly different average.

In the globalized world, in which organizations are embedded, the changes appear to be increasingly complex, characterized by increasing demands for speed, quality, low cost, flexibility and customer satisfaction. In this context, to ensure high levels of business competitiveness, the companies must act quickly and flexibly, in a pro-active, innovating their services, processes and technology, focused on customer needs and market.

H0: The constraint "Alignment between technology and business" is the same for all e-business maturity stages.

H9: There are at least two stages of maturity with significantly different average.

According to (Kearns and Lederer, 2000) alignment between IT and the business plan is necessary to achieve the objectives of the business and capitalize on the use of IT, helping and ensuring that investments in IT are correctly used to support these objectives and increase competitive advantage through the use of IT.

H0: The constraint "Lack of qualified human resources" is the same for all e-business maturity stages.

H10: There are at least two stages of maturity with significantly different average.

According to the OECD report, the lack of qualified human resources is a barrier to the development of electronic business (OECD, 1999).

H0: The constraint "People coordination" is the same for all e-business maturity stages.

H11: There are at least two stages of maturity with significantly different average.

A business model is a mediated construction between technology and business (Chesbrough and Rosenbloom, 2002). A poor coordination between the leaders of these two areas may be a constraint to the development of e-business in the organization.

H0: The constraint "Resistance to change" is the same for all e-business maturity stages.

H12: There are at least two stages of maturity with significantly different average.

Innovation is a major factor leading to competitive advantage of organizations. Resistance to change is inevitable, even if this represents growth and development. In this context, managers should be prepared to manage resistance to change (Fine, 1986).

HO: The e-business maturity is the same for all activity sectors.

H13: There are at least two activity sectors with significantly different average.

It has been proven in literature that the characteristics of each activity sector influence the adoption of e-business (Mehrtens et al., 2001), with benefits for the companies which take on e-business. 


\section{DATA COLLECTION}

A questionnaire was developed to collect data. Prior to distribution, a series of pilot tests were conducted with a group of 10 information system director enterprises from a range of businesses and a group of $5 \mathrm{PhD}$ students. The test participants were asked to complete the questionnaire and then evaluate the questionnaire and make suggestions. After the questionnaire had been finalized, it was administered to the 1000 managing directors of the biggest (according to the amount of business) Portuguese enterprises. The information about the enterprises was given by the Portuguese National Institute of Statistics (INE, 2007).

We chose the questionnaire and not other method of data collection, such as interview, for reasons of time and cost. Besides the questionnaire as a tool of data collection, there are other studies that address similar issues, namely case studies, and which lead to similar results (Gibbs et al., 2003).

A total of 1000 presentation letters of the questionnaire were sent by post and 774 by e-mail to some of the 1000 companies that have an e-mail address. This presentation letter and e-mail referred the website, the login and password for the survey. All the enterprises had a login and a password to access to the questionnaire to guarantee that each enterprise would only answer once.

The presentation letters of the questionnaire were distributed in November 2007.

Within the cut-off date, set at 3 weeks after the survey was distributed, there were 208 returned questionnaires. Of the 208 questionnaires, 70 were incomplete (32 do not answer about its maturity stage and 38 do not answer the question where the constraints associated to each maturity stage are questioned), prompting their removal from the sample as this might increase the error and bias of the survey. Effectively, 138 usable responses were included in the sample for further analysis, representing response rate of $13,8 \%$. This is well above the normally low response rate of $5-10 \%$ for a postal survey (Alreck and Settle, 1985; Barnett, 1991).

\section{RESULTS}

\subsection{Descriptive Results}

Within the sample, $48,6 \%$ are directors, $5,8 \%$ general directors, 5,8\% administrators, 16,7\% executives and $23,2 \%$ have other function in the enterprise. The respondents who answered "Other" are the majority responsible for Information Systems (IS) department. Only $11,6 \%$ of the sample did Secondary school, all the others are graduated or post-graduated.

Respondents were categorized into seven industry sectors: Manufacturing, Information and Communication Activities, Retail and Wholesale, Financial Services, Commerce of Vehicles, Civil Construction, Transports and Others. The final sample, comprised of 138 enterprises, consists of $25 \%$ manufacturing firms, $26 \%$ retail \& wholesale, 4\% information and communication activities, 9\% financial services, $8 \%$ civil construction, 8\% transport, $7 \%$ commerce of vehicles and $13 \%$ enterprises of various categories.

Figure 2 shows the evolution of e-business maturity between 2005 and 2007 in the 1000 biggest Portuguese enterprises. It is interesting to verify that in 2005 almost half of the enterprises were between stage 1 and stage 2 and in 2007 approximately 64\% were between stage 4 and stage 6 . This shows that enterprises are sensitive to e-business. There could be a natural tendency for people, who would like to make the questionnaire completion easier. Nevertheless, according to the report "The Information Society in Portugal 2007" 100\% of large firms has Internet connection. $97 \%$ are connected to the Internet by broadband, occupying Portugal, the 7 the place ranking in the EU27. About 7 in 10 companies use the Internet to interact with organizations and public authorities, which represents an increase of 20\% from 2006 to 2007. $86 \%$ of large companies have an Internet presence (UMIC, 2007). This report may be an indicator that the questionnaires were answered seriously.

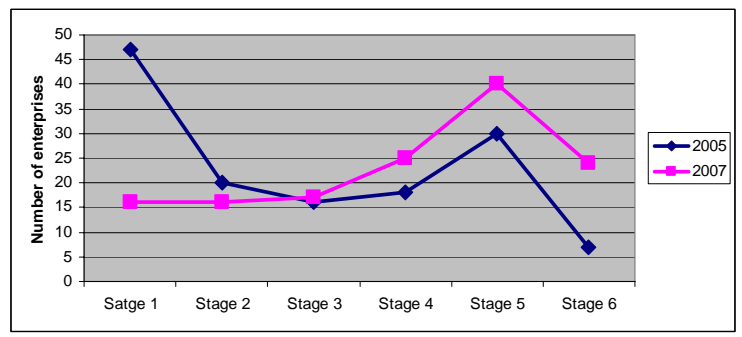

Figure 2: Evolution of the e-business maturity.

Respondents were also asked to rate the concerns/problems acting as constraints for the development of their e-business initiatives. Respondents scored each item on a 7-point scale, where 1 is not problematic and 7 is very problematic. The responses are reported in Table 1. 
Table 1: Major constraints encountered in each year.

\begin{tabular}{|c|c|c|c|c|c|c|}
\hline \multirow[b]{2}{*}{ Constraint } & \multicolumn{2}{|c|}{$\begin{array}{c}2005 \\
(\mathrm{~N}=138)\end{array}$} & \multicolumn{2}{|c|}{$\begin{array}{c}2006 \\
(\mathrm{~N}=138)\end{array}$} & \multicolumn{2}{|c|}{$\begin{array}{c}2007 \\
(\mathrm{~N}=138)\end{array}$} \\
\hline & Mean & SD & Mean & SD & Mean & SD \\
\hline $\begin{array}{l}\text { The technology existent is not the } \\
\text { most adequate to e-business }\end{array}$ & 3,13 & 1,89 & 2,83 & 1,80 & 2,53 & 1,77 \\
\hline Cost of e-business & 3,61 & 1,93 & 3,38 & 1,84 & 3,28 & 1,84 \\
\hline $\begin{array}{l}\text { Uncertainty with aspects related to } \\
\text { security }\end{array}$ & 3,23 & 1,83 & 3,02 & 1,69 & 2,80 & 1,66 \\
\hline $\begin{array}{l}\text { Conflict with traditional trading } \\
\text { partners }\end{array}$ & 3,67 & 2,04 & 3,46 & 1,96 & 3,28 & 2,03 \\
\hline $\begin{array}{l}\text { Conflict with traditional business } \\
\text { and e-business initiatives }\end{array}$ & 3,77 & 2,00 & 3,59 & 1,97 & 3,41 & 1,98 \\
\hline $\begin{array}{l}\text { Lack of senior management } \\
\text { support }\end{array}$ & 2,62 & 1,77 & 2,41 & 1,62 & 2,23 & 1,52 \\
\hline Managing e-business project & 3,08 & 1,76 & 2,91 & 1,67 & 2,76 & 1,67 \\
\hline Reengineering business processes & 3,69 & 1,85 & 3,51 & 1,79 & 3,33 & 1,86 \\
\hline Business-technology alignment & 3,75 & 1,91 & 3,46 & 1,82 & 3,22 & 1,83 \\
\hline $\begin{array}{l}\text { Access to technical skills and } \\
\text { expertise }\end{array}$ & 3,39 & 1,77 & 3,16 & 1,64 & 2,97 & 1,66 \\
\hline $\begin{array}{l}\text { Coordination between business- } \\
\text { technology people }\end{array}$ & 3,27 & 1,77 & 3,06 & 1,69 & 2,93 & 1,70 \\
\hline Resistance to change & 3,41 & 3,89 & 3,15 & 1,73 & 2,93 & 1,69 \\
\hline
\end{tabular}

The maturity of the enterprises increased over the years, and with this evolution in the maturity stage it is interesting to verify that the major problems are always the same ones, but simultaneously, they have diminished over time.

Overall, it is reported that conflict with traditional business and e-business initiatives, conflict with traditional trading partners and reengineering business processes are the greater constraints, although they have values less than 4 . The less problematic is the lack of senior management support. It is important to remind that we are talking about the biggest Portuguese enterprises.

\subsection{Hypotheses Testing}

To test our hypotheses we used the Kruskal-Wallis test, since this is a more powerful test when using ordinal variables (Maroco, 2003). The results are show in Table 2.

Table 2: Hypotheses Results using Kruskal-Wallis test.

\begin{tabular}{ccccccc}
\hline & \multicolumn{2}{c}{2005} & \multicolumn{2}{c}{2006} & \multicolumn{2}{c}{2007} \\
\hline Hypotheses & $\begin{array}{c}\text { Chi- } \\
\text { Square }\end{array}$ & p-value & $\begin{array}{c}\text { Chi- } \\
\text { Square }\end{array}$ & p-value & $\begin{array}{c}\text { Chi- } \\
\text { Square }\end{array}$ & p-value \\
\hline$H 1$ & 14,895 & 0,011 & 11,339 & 0,045 & 19,004 & 0,002 \\
\hline$H 2$ & 5,472 & $\mathbf{0 , 3 6 1}$ & 6,969 & $\mathbf{0 , 2 2 3}$ & 5,241 & $\mathbf{0 , 3 8 7}$ \\
\hline$H 3$ & 6,178 & $\mathbf{0 , 2 8 9}$ & 2,836 & $\mathbf{0 , 7 2 5}$ & 10,547 & $\mathbf{0 , 0 6 1}$ \\
\hline$H 4$ & 20,596 & 0,001 & 27,017 & 0,000 & 29,984 & 0,000 \\
\hline$H 5$ & 28,407 & 0,000 & 29,67 & 0,000 & 37,277 & 0,000 \\
\hline$H 6$ & 15,598 & 0,008 & 19,225 & 0,002 & 15,976 & 0,007 \\
\hline$H 7$ & 11,29 & 0,046 & 11,238 & 0,047 & 19,58 & 0,001 \\
\hline$H 8$ & 18,702 & 0,002 & 23,573 & 0,000 & 25,815 & 0,000 \\
\hline$H 9$ & 22,203 & 0,000 & 20,532 & 0,001 & 25,287 & 0,000 \\
\hline$H 10$ & 15,619 & 0,008 & 9,09 & 0,106 & 11,459 & 0,043 \\
\hline$H 11$ & 12,453 & 0,029 & 15,387 & 0,009 & 24,094 & 0,000 \\
\hline$H 12$ & 14,038 & 0,015 & 15,577 & 0,008 & 21,027 & 0,001 \\
\hline$H 13$ & 15,56 & 0,029 & 14,213 & 0,048 & 16,454 & 0,021 \\
\hline
\end{tabular}

The test results lead us to conclude that for all hypotheses, with the exception of $\mathrm{H} 2$ and $\mathrm{H} 3$, there are at least two stages of maturity with significantly different average for each of the years, since the $p$ values are always below 0,05 . As such, we can confirm all the hypotheses except $\mathrm{H} 2$ and H3. In other words, we can't say that the cost of e-business and the uncertainty with aspects related to security are more or less problematic depending on the maturity stage of the organization.

\section{CONCLUSIONS}

It is said that in the last decade e-business has revolutionized the business world. This study attempts to explore the constraints associated to ebusiness evolution in big enterprises. The study found that big enterprises are sensitive to e-business and that they had an evolution of maturity from 2005 to 2007. This evolution was probably caused by some initiatives launched by governments. In the last few years several initiatives have been taken and, at the end of 2005, the Technological Plan was launched. This plan aims at mobilizing the Portuguese society to overcome the modernization challenge the country has been facing in the last years. This plan, included in a broader plan - the National Action Program for Growth and Jobs, 2005-2008 - is based on three main axes:

Knowledge - To qualify the Portuguese for the knowledge society, fostering structural measures which aim at enhancing the average qualification level of the population, implementing a broad and diversified lifelong learning system and mobilizing the Portuguese for the Information Society;

Technology - To overcome the scientific and technological gap, reinforcing public and private scientific and technological competences;

Innovation - To boost innovation, helping the productive chain to get adapted to the challenges of globalization by means of the diffusion and development of new procedures, organizational systems, services and goods.

In 2006 the program “On-the-Spot-Firm” was launched. This program enabled the establishment of certain online companies in less than one hour. The European Commission acknowledged the relevance of this initiative and recently granted Portugal with the European Enterprise Award, on the category "Red Tape Reduction".

The constraints associated to change, are normally the most problematic. Gibbs et al. (2003) 
conclude that for many European countries, cultural resistance to change and innovation is at the root of resistance to e-business. And Portugal, we believe is no exception.

This study was also intended to test a set of factors that could act as constraints to e-business development. Were confirmed eleven of the thirteen hypotheses.

We are doing the same research on Small and Medium Enterprises (SMEs), because perhaps the great part of the partners of the big companies are SMEs. And if SMEs are in a low stage of maturity they will be able to influence the maturity stage of big companies and, mainly, its evolution.

\section{REFERENCES}

Alreck, L., Settle, B., 1985. The survey research handbook. Illinois, Irwin.

Barnett, V., 1991. Sample survey: Principles and methods. Edward Arnold, London.

Bakry, S., Bakry F., 2001. A strategic view for the development of e-business. International Journal of Network Management, 11: 103-112.

Chepaitis, E., 2002. Soft barriers to ICT application in development: trust and information quality in Russia. Journal of International Development, 14: 51-60.

Chesbrough H., Rosenbloom, R., 2002. The role of the business model in capturing value from innovation: Evidence from Xerox Corporation's technology spinoff companies. Industrial and Corporate Change, 11(3): 529-555.

Eisenmann, T., 2007. Managing Networked Businesses: Course Overview for Educators. Harvard Business School Press. Boston.

Fine, S., 1986. Technological innovation, diffusion and resistance: A historical perspective. Journal of Library Administration, 7: 83-108.

Gibbs, J., Kraemer, K., Dedrick, J., 2003. Environment and Policy Factors Shaping Global E-Commerce Diffusion: A Cross-Country Comparison. The Information Society, 19(1): 5-18.

Grembergen W., Amenlinckx, I., 2002. Measuring and managing e-business projects through the balanced scorecard. In Proceedings of the 35th Hawaii International Conference on System Sciences, January 2002, 258-266.

Grover, V., Teng, J., Segars, A., Fiedler K., 1998. The influence of information technology diffusion and business process change on perceived productivity: The IS executive's perspective. Information \& Management, 34(3): 141-15.

INE, 2007. National Institute of Statistics of Portugal. October 2007.

Kalakota, R., Whinston, A., 1996. Frontiers of Electronic Commerce. Addison-Wesley, London.
Kalakota, R. and M. Robinson, 2000. E-business 2.0: Roadmap for Success, Addison-Wesley.

Kalakota, R., Robinson, M., 2003. E-business 2.0: Roadmap for Success. Addison-Wesley, 2nd edition.

Kearns, G., Lederer, A., 2000. The effect of strategic alignment on the use of IS based resources for competitive advantage. Journal of Strategic Information Systems, 9: 265-293.

Laudon, K., Traver, C., 2006. E-commerce Business, Technology, Society. Prentice Hall.

Legris, P., Ingham, J. and Collerette, P., 2003. "Why do people use information technology? A critical review of the technology acceptance model”, Information \& Management, 40: 191-204.

Lertwongsatien, C. and Wongpinunwatana, N., 2003. Ecommerce Adoption in Thailand: An Empirical Study of Small and Medium Enterprises (SMEs). Journal of Global Information Technology Management. 6(3): 67-83.

Maroco J., 1003. Análise Estatística com utilização do SPSS, Edições Silabo.

Martin, L. M., Matlay, H., 2003. Innovative Use of the Internet in Established Small Firms. Qualitative Market Research: An International Journal 6(1): 1826.

Mehrtens, J., Cragg, P., Mills, A., 2001. A model of Internet adoption by SME's. Information Management. 39:165-176.

OECD, 1999. SMEs and Electronic Commerce: Proposals for Work, Working Party on Small and Medium-Sized Enterprises, DSTI/IND/PME (99)11/REV1, Paris.

Phan, D., 2003. E-business Development for Competitive Advantages: a Case Study. Information \& Management. 40: 581-590.

Porter, M., (2001), Strategy and the Internet, Harvard Business Review, March, 63-78.

Prananto, A., McKay, J., Marshall, P., 2003. The spectrum of e-business maturity in Australian SMEs: A multiple case study approach to the applicability of the stages of growth for e-business model. In 11th European Conference on Information Systems (ECIS). Napoli, Italy.

Saxowsky, D., Duncan, M., 1998. Understanding agriculture's transition into the 21st century: challenges, opportunities, consequences and alternatives, Report 181, Department of Agricultural Economics, North Dakota State University.

Sewell, M., McCarthey, I., 2001. E-business and its role in small business networks. Proceedings of the Manufacturing Information Systems. In $4^{\text {th }}$ SMESME International Conference, Aalborg, Denmark, 214-221

Sorenson, R. L., 2000. The Contribution of Leadership Style and Practices to Family and Business Success. Family Business Review, 13(3): 183-200.

UMIC, 2007. A Sociedade da Informação em Portugal 2007, www.umic.pt Accessed May 2008.

Worner, B., 2002., "Choosing the right security infrastructure for E-Business Success", Information Security Journal: A global Perspective, 11:1, 51-56. 